\title{
Tobacco use and its clinical correlates among Psychiatric in-patients at a tertiary care Psychiatric Hospital: A cross sectional study
}

\author{
Pendota Swetha $^{1}$, Shanti Mohan Kethawath ${ }^{2 *}$, Sireesha Srinivasa Rao ${ }^{3}$
}

${ }^{1}$ Junior Resident, ${ }^{2}$ Assistant Professor, ${ }^{3}$ Professor and Deputy Superintendent, ${ }^{1,3}$ Dept. of Psychiatry, Institute of Mental Health, Osmania Medical College, Hyderabad, Telangana, ${ }^{2}$ MNR Medical College \& Hospital, Sangareddy, Telangana, India

\section{*Corresponding Author: Shanti Mohan Kethawath}

Email: shantimohankethawath.143@gmail.com

\begin{abstract}
Background: Prevalence of tobacco use is variable among psychiatric illness across the world. Tobacco consumption may predispose or worsen the psychiatric illnesses.

Aims: To study the prevalence of tobacco use among psychiatric in-patients and to study the association between various sociodemographic variables and clinical variables with tobacco use.

Materials and Methods: A cross sectional study was conducted among psychiatric in -patients $(\mathrm{n}=200)$ at a tertiary care psychiatric hospital. Consecutive sampling technique was applied. A semi-structured proforma was applied to capture the socio-demographic and clinical details of the participants. The Fagerstrom Test for Nicotine Dependence (FTND) was applied to assess for the tobacco dependence.

Results: Prevalence of current tobacco use among the study population was 39.5\%. Among the psychiatric illness, prevalence of tobacco use is significantly higher in substance use disorders when compared with mood disorders $(\chi 2=7.757, \mathrm{p}=0.005)$ and schizophrenia and other psychotic disorders $(\chi 2=24.093, \mathrm{p}<0.01)$. Tobacco use is significantly associated with male gender $(\chi 2=20.820, \mathrm{p}<0.01)$, employment $(\chi 2=7.860, \mathrm{p}=0.005)$ and marital status $(\chi 2=7.930, \mathrm{p}=0.019)$ among psychiatric patients.

Conclusion: Prevalence of tobacco use was found to be high among psychiatric population. There is a need to focus on the adequate management of tobacco use along with primary psychiatric conditions.
\end{abstract}

Keywords: Nicotine, Psychiatric in-patients, Smoking, Tobacco.

\section{Introduction}

Tobacco use disorder is one of the major health concern. It is anticipated that, there will be 1.1 billion smokers all over the world, by $2025 .{ }^{1}$ Smoking was the second leading risk factor for deaths and was responsible for 7.10 million deaths in 2017 globally. ${ }^{2}$ In India, about $28.6 \%$ of the population consume tobacco in any form, $10.7 \%$ uses tobacco in the form of smoking and $21.4 \%$ uses smokeless form of tobacco. ${ }^{3}$ It was found that smoking was significantly higher in psychiatric outpatients when compared to general population, ${ }^{4}$ and psychiatric patients have a higher chances of being a current smoker and have lower cessation rates. ${ }^{5}$ Heavy smoking and severe nicotine dependence were frequently seen in smokers with schizophrenia when compared to general population. ${ }^{6}$ Persons with nicotine dependence had higher rates of major depression and anxiety disorders. ${ }^{7}$ Severity of mental illness is also affected by tobacco consumption as it was found that schizophrenia patients who consumed tobacco had significantly higher positive symptom scores compared to non-users. ${ }^{8}$ Tobacco-related medical conditions comprised approximately $53 \%$ of total deaths in the schizophrenia, $48 \%$ in the bipolar, and $50 \%$ in the depression cohorts. ${ }^{9}$ Patients with tobacco dependence also tended to use other substances like khat and alcohol which have their independent impact on medication adherence and prognosis of the mental illness. ${ }^{10}$ In patients with bipolar disorder, tobacco smoking, both independently and in the presence of other substance use, was significantly associated with recurrent suicide attempts. ${ }^{11}$ Thus, tobacco consumption may predispose or worsen the psychiatric illnesses.
A cross sectional study among 270 psychiatric patients found that $35.6 \%$ were smokers, of whom, $53.2 \%$ presented with high or very high nicotine dependence. $33.3 \%$ of smokers were schizophrenic patients. ${ }^{12}$ The greater difficulty to quit smoking was positively associated with a higher frequency of previous psychiatric hospitalizations (Fisher $=0.042$ ). Another study assessed patterns of smoking and nicotine dependence among 816 psychiatric inpatients and found that $70 \%$ of participants were smokers. It was found that depressed patients smoked less than schizophrenic patients $(\mathrm{P}=0.04)$. Smoking was significantly related with advanced age $(\mathrm{P}<0.001)$, male sexuality $(\mathrm{P}<0.001)$, hookah consumption $(\mathrm{P}<0.001)$, and depression. ${ }^{13}$ In a crosssectional study done among 305 male and 117 female mental health service users, $18.5 \%$ of study population were dependent on tobacco. Amongst people with tobacco dependence, 57.7, 29.5 and 12.8\% had moderate, high and very high level of tobacco dependence respectively. ${ }^{10}$ In a study done among 998 psychiatric inpatients, in India, 36\% of the study population were found to be tobacco users, of which $65 \%$ were dependent on nicotine. Significant predictors of tobacco use were male gender, older age, lower levels of education, diagnosis of bipolar disorder, and substance use. However, there was no significant association found between nicotine dependence and specific psychiatric diagnosis. $^{14}$ In a cross-sectional study done among 303 psychiatric in-patients at a tertiary care hospital in North India, $39.9 \%$ were found to be tobacco users. Comorbid other substance use disorders and psychiatric comorbidities were higher in tobacco users than nonusers of tobacco. Comorbid alcohol use (38\%) and cannabis use (34\%) were also higher 
in the tobacco user group. ${ }^{15}$ Thus, tobacco use among psychiatric patients is variable across the study setting and regions. Further, sociocultural and economic factors could influence smoking behavior especially in a developing country like India. In countries like India smoking is often prohibited by familial, cultural and religious practices. Thus, many factors influence the use of tobacco among psychiatric patients. There is a vast literature from western countries about tobacco use in psychiatric patients. However, in India, literature pertaining to use of tobacco in psychiatric patients is limited. Therefore, we aimed to study prevalence of tobacco use among psychiatric in-patients. We further aimed to study the association between various sociodemographic and clinical variables with tobacco use.

\section{Materials and Methods}

The study was conducted at tertiary care psychiatric hospital, Institute of Mental Health, Hyderabad. Study was conducted after obtaining ethics committee approval from Osmania medical college ethics committee. The study was performed on the psychiatric in-patients who got admitted in open wards between $1^{\text {st }}$ June 2020 to $1^{\text {st }}$ august 2020. Consecutive sampling technique was used to select the study sample. Patients having reliable informant, able to give informed consent, all psychiatric diagnosis like schizophrenia, bipolar affective disorders, substance use disorders, neurotic disorders and others of both male and female genders were included in the study. Non consenting patients and those not having reliable informant were excluded from the study. A total of 206 patients who were admitted in open wards were approached to participate in the study and they were explained in detail about the objectives, purpose and procedure of the study in language they can understand. 200 patients gave their consent for the study. All the demographic details of patient's such as Name, Age, Sex, Education level, Occupation, Marital status, Residency were captured using a demographic proforma. All the relevant clinical details about tobacco use were taken. Details about primary psychiatric diagnosis were taken from the medical records. For the purpose of this study, "Current tobacco use" was empirically defined as the usage of tobacco with in the past 30 days before the assessment. Clinically, the diagnosis of tobacco dependence was established as per International Classification of Disorders- $10^{\text {th }}$ edition. The Fagerstrom Test for Nicotine Dependence (FTND) was applied for severity of dependence, which is a brief six item instrument to assesses severity of nicotine dependence available for both smoke and smokeless forms of tobacco. Based on the form of tobacco used by the subject, FTND was applied for smokers and FTND-ST was applied for smokeless tobacco users. ${ }^{16,17}$

Descriptive statistics have been used to tabulate sociodemographic variables of the study sample. Descriptive statistics were also used to tabulate the frequencies of clinical characteristics of patients and tobacco related characteristics of all psychiatric patients. Chi-square test ( $\chi 2$ tests) was used to look for association of sociodemographic \& clinical variables with presence / absence of tobacco use. Level of statistical significance was kept at $p<0.05$ and all the tests were two tailed. SPSS version 26 was used for data analysis.

\section{Results}

A total of 206 patients were screened for the study and six patients did not give consent for participation in the study (97\% response rate).

\section{Sociodemographic characteristics of the patients}

As shown in Table 1, 63\% of the study population were males, $37 \%$ were females. Mean age of the study participants was 33.09 (S.D 9.96) years. $43.5 \%$ were married and $41 \%$ were unmarried. $27 \%$ of them had attended secondary education, whereas $17 \%$ were not formerly educated. Most of them are from nuclear family $(73.5 \%)$ and Hindu religion $(80.5 \%)$. More than half of the participants are unemployed $(54 \%)$ and from urban background $(60 \%)$.

Table 1: Sociodemographic characteristics of patients

\begin{tabular}{|c|c|}
\hline Variable & \begin{tabular}{|l|} 
Frequency (Percentage) \\
Mean (SD) \\
\end{tabular} \\
\hline $\begin{array}{l}\text { Gender } \\
\text { Male } \\
\text { Female }\end{array}$ & $\begin{array}{l}126(63) \\
74(37)\end{array}$ \\
\hline Age & $33.09+9.963$ \\
\hline $\begin{array}{l}\text { Marital status } \\
\text { Married } \\
\text { Unmarried } \\
\text { Others } \\
\end{array}$ & \begin{tabular}{|l}
$87(43.5)$ \\
$82(41)$ \\
$31(15.5)$ \\
\end{tabular} \\
\hline $\begin{array}{l}\text { Educational status } \\
\text { Primary } \\
\text { Secondary } \\
\text { Intermediate } \\
\text { Graduation } \\
\text { Illiterate } \\
\end{array}$ & $\begin{array}{l}34(17) \\
54(27) \\
28(14) \\
49(24.5) \\
35(17.5) \\
\end{array}$ \\
\hline $\begin{array}{l}\text { Religion } \\
\text { Hindu } \\
\text { Muslim } \\
\text { Christian }\end{array}$ & $\begin{array}{l}161(80.5) \\
33(16.5) \\
6(3)\end{array}$ \\
\hline $\begin{array}{l}\text { Occupational status } \\
\text { Unemployed } \\
\text { Employed }\end{array}$ & $\begin{array}{l}108(54) \\
92(46)\end{array}$ \\
\hline $\begin{array}{l}\text { Residency } \\
\text { Rural } \\
\text { Urban }\end{array}$ & $\begin{array}{l}80(40) \\
120(60)\end{array}$ \\
\hline $\begin{array}{l}\text { Family } \\
\text { Nuclear } \\
\text { Extended nuclear } \\
\text { Joint }\end{array}$ & $\begin{array}{l}147(73.5) \\
15(7.5) \\
38(19)\end{array}$ \\
\hline
\end{tabular}

\section{Clinical characteristics of the patients}

As shown in table 2, the most common psychiatric diagnosis was schizophrenia and other psychotic disorders (41.5\%) followed by mood disorders (26.5\%) and substance use disorders (18.5\%). Neurotic, stress - related and somatoform disorders constituted $6 \%$ of cases. Other psychiatric disorders constituted $7.5 \%$ of the cases. More than half of the $(67 \%)$ 
patients had history of suicide attempt and 54\% were previously hospitalized. $43.5 \%$ of patients are using one of the other psychoactive substance (irrespective of tobacco).

Table 2: Clinical characteristics of patients

\begin{tabular}{|l|l|}
\hline Variable & $\begin{array}{l}\text { Frequency } \\
\text { (Percentage) }\end{array}$ \\
\hline $\begin{array}{l}\text { Schizophrenia and other psychotic } \\
\text { disorders }\end{array}$ & $83(41.5)$ \\
$\begin{array}{l}\text { Mood disorders } \\
\text { Mental and behavioural disorders due } \\
\text { to use of substance }\end{array}$ & $53(26.5)$ \\
$\begin{array}{l}\text { Neurotic, stress- related and } \\
\text { somatoform disorders } \\
\text { Others }\end{array}$ & $12(6)$ \\
\hline $\begin{array}{l}\text { History of suicidal attempt } \\
\text { Yes }\end{array}$ & $15(7.5)$ \\
No & $66(33)$ \\
\hline History of prior hospitalization & $134(67)$ \\
Yes & $92(46)$ \\
No & $108(54)$ \\
\hline $\begin{array}{l}\text { Use of other psychoactive substance } \\
\text { Yes }\end{array}$ & $87(43.5 \%)$ \\
No & $113(56.5 \%)$ \\
\hline
\end{tabular}

Tobacco related characteristics of all psychiatric patients Tobacco related characteristics of the participants is shown in table 3. Current prevalence of tobacco use among the psychiatric in-patients was $39.5 \%$ (79). Among the tobacco users $65(82.2 \%)$ were male and $14(17.7 \%)$ were female. More than one fourth $(27.8 \%)$ of tobacco users, initiated tobacco when they were less than 18 years. Of all tobacco users $(n=79), 37$ were using tobacco only in smoking form of, 26 were using only smokeless form of tobacco, 16 were using tobacco in both forms. Total Number of smokers in our sample is 53, it includes both the persons using tobacco only in the form smoking and those using both forms of tobacco. Similarly, number of patients using smokeless form of tobacco is 42 . More than three fourth of the tobacco users were using tobacco in dependence pattern $(n=70,88 \%)$. Four percent $(n=8)$ of patients had a previous history of tobacco dependence and are currently maintaining abstinence.

Prevalence of tobacco use is high in substance use disorders $(n=28,75.6 \%)$, followed by mood disorders $(n=24,45.2 \%)$ and schizophrenia and other psychotic disorders $(n=23$, $27.7 \%$ ). Prevalence of tobacco use in neurotic, stress- related and somatoform disorders and other psychiatric disorders is less than five percent $(1.2 \% \& 3.7 \%$ respectively).

Table 3: Tobacco related characteristics of all psychiatric patients

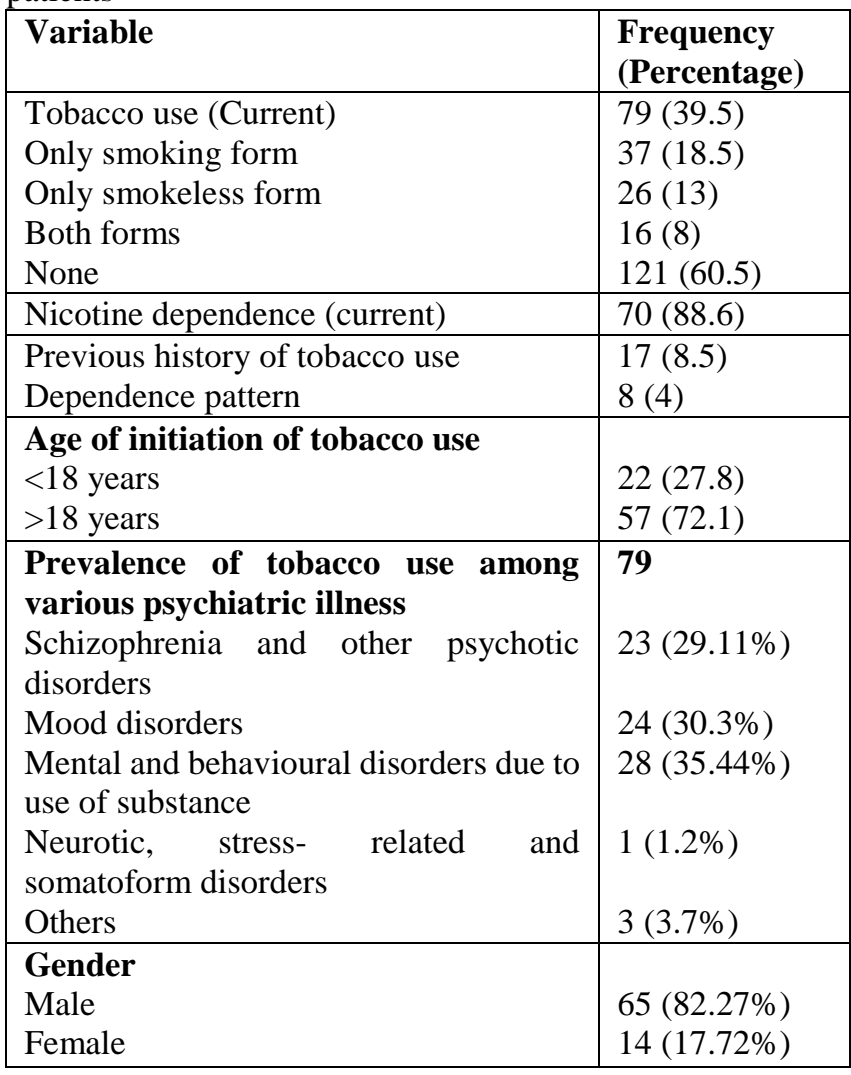

Understanding about tobacco use among tobacco users with psychiatric illness

As shown in the table 4, most common reason for initiation of tobacco use was being coaxed by friends in both smoking $(58.4 \%)$ and smokeless $(52.3 \%)$ tobacco users. More than three fourth of the tobacco smokers $(88.6 \%)$ perceive that tobacco products are psychoactive substances however, $45 \%$ of smokers believe that they are not addicted to smoking. Similarly, two third of smokeless tobacco users $(66.6 \%)$ perceive that tobacco products are psychoactive substances however, $47.6 \%$ of smokeless tobacco users believe that they are not addicted to smoking.

Table 4: Understanding about tobacco use among tobacco users with psychiatric illness

\begin{tabular}{|c|c|c|}
\hline Understanding about tobacco use & $\begin{array}{l}\text { Smoking tobacco users } \\
(\mathrm{n}=53, \text { Exclusively smokers } \\
\text { and those who smoke and chew } \\
\text { tobacco) }\end{array}$ & $\begin{array}{l}\text { Smokeless tobacco users } \\
\text { ( } \mathrm{n}=42 \text {, Exclusively smokeless } \\
\text { tobacco user and those who chew } \\
\text { tobacco and smoke) }\end{array}$ \\
\hline Reason for initiation of tobacco use & & \\
\hline Enjoyment & $7(13.20 \%)$ & $5(11.9 \%)$ \\
\hline Fashionable & $2(3.77 \%)$ & $1(2.38 \%)$ \\
\hline Friends & $31(58.49 \%)$ & $22(52.38 \%)$ \\
\hline Experiment & $7(13.20 \%)$ & $9(21.42 \%)$ \\
\hline Stress & $5(9.43 \%)$ & $5(11.9 \%)$ \\
\hline
\end{tabular}




\begin{tabular}{|l|l|l|}
\hline $\begin{array}{l}\text { Do you think tobacco products are } \\
\text { psychoactive substances }\end{array}$ & \\
Yes & $\begin{array}{l}4(88.67 \%) \\
\text { No }\end{array}$ & $28(66.66 \%)$ \\
Don't know think you are addicted to & $2(3.77 \%)$ & $11(26.19 \%)$ \\
\hline Do you think) & \\
smoking tobacco & $27(50.94 \%)$ & \\
Yes & $24(45.28 \%)$ & $22(52.38 \%)$ \\
No & $2(3.77 \%)$ & $20(47.61 \%)$ \\
Don't know & 0 \\
\hline
\end{tabular}

Association of sociodemographic and clinical variables with presence / absence of tobacco use:

As shown in table 5, Tobacco use is significantly higher in males compared to female psychiatric patients $(\mathrm{p}<0.01)$ and more in married when compared to unmarried, divorced or separated $(\mathrm{p}=0.019)$. Similarly, tobacco use is higher in employed compared to unemployed psychiatric patients $(\mathrm{p}=0.005)$. However, no significant association was found between tobacco use and other socio-demographic variables like religion, type of family, residency ( $p>0.05)$.

Among the psychiatric illnesses, tobacco use is significantly more common in substance use disorders as compared to schizophrenia and other psychotic disorders $(\chi 2=24.093, p<0.01)$ and mood disorders $(\chi 2=7.757, p=0.005)$. Similarly, tobacco use is significantly more common in mood disorders as compared to schizophrenia and other psychotic disorders $(\chi 2=4.416$, $\mathrm{p}=0.036$ ). Further, tobacco use is significantly more common in those with other substance use as a comorbid condition, compared to those without other comorbid substance use $(60.393, \mathrm{p}<0.01)$. However, no significant association was found between tobacco use and suicidal attempt and previous history of hospitalization ( $p>0.05)$.

Table 5: Association of sociodemographic \& clinical variables with presence / absence of tobacco use

\begin{tabular}{|c|c|c|c|}
\hline Variable & \begin{tabular}{|l|} 
Tobacco use \\
Present $(n=79)$ \\
\end{tabular} & $\begin{array}{l}\text { Tobacco use } \\
\text { Absent }(n=121)\end{array}$ & Chi square (df), $p$ \\
\hline $\begin{array}{l}\text { Gender } \\
\text { Male } \\
\text { Female }\end{array}$ & $\begin{array}{l}65(82.27 \%) \\
14(17.72 \%)\end{array}$ & $\begin{array}{l}61(50.41 \%) \\
60(49.58 \%)\end{array}$ & $20.820(1),<0.01^{*}$ \\
\hline $\begin{array}{l}\text { Marital status } \\
\text { Married } \\
\text { Unmarried } \\
\text { Others } \\
\end{array}$ & $\begin{array}{l}40(50.63 \%) \\
23(29.11 \%) \\
16(20.25 \%) \\
\end{array}$ & $\begin{array}{l}47(38.84 \%) \\
59(48.76 \%) \\
15(2.39 \%) \\
\end{array}$ & $7.930(2), 0.19$ \\
\hline $\begin{array}{l}\text { Religion } \\
\text { Hindu } \\
\text { Muslim } \\
\text { Christian }\end{array}$ & $\begin{array}{l}60(75.94 \%) \\
13(16.45 \%) \\
6(7.5 \%) \\
\end{array}$ & $\begin{array}{l}97(80.16 \%) \\
20(16.52 \%) \\
4(3.30 \%)\end{array}$ & $1.867(2), 0.393$ \\
\hline $\begin{array}{l}\text { Type of family } \\
\text { Nuclear } \\
\text { Extended Nuclear } \\
\text { Joint } \\
\end{array}$ & \begin{tabular}{|l}
$52(65.82 \%)$ \\
$9(11.39 \%)$ \\
$18(22.78 \%)$ \\
\end{tabular} & $\begin{array}{l}95(78.51 \%) \\
6(4.9 \%) \\
20(16.52 \%) \\
\end{array}$ & 4.669 (2), 0.097 \\
\hline $\begin{array}{l}\text { Residency } \\
\text { Rural } \\
\text { Urban }\end{array}$ & $\begin{array}{l}32(40.50 \%) \\
47(59.49 \%)\end{array}$ & $\begin{array}{l}48(39.6 \%) \\
73(60.33 \%)\end{array}$ & $0.014(1), 0.906$ \\
\hline $\begin{array}{l}\text { Occupational status } \\
\text { Unemployed } \\
\text { Employed }\end{array}$ & $\begin{array}{l}33(41.77 \%) \\
46(58.22 \%) \\
\end{array}$ & $\begin{array}{l}75(61.8 \%) \\
46(38.01 \%)\end{array}$ & $7.860(1), 0.005^{*}$ \\
\hline $\begin{array}{l}\text { Suicidal attempt } \\
\text { Yes } \\
\text { No }\end{array}$ & $\begin{array}{l}30(37.77 \%) \\
49(62.02 \%)\end{array}$ & $\begin{array}{l}36(29.75 \%) \\
85(70.24 \%)\end{array}$ & $1.462(1), 0.227$ \\
\hline $\begin{array}{l}\text { Previous hospitalization } \\
\text { Yes } \\
\text { No }\end{array}$ & $\begin{array}{l}35(44.30 \%) \\
44(55.69 \%) \\
\end{array}$ & $\begin{array}{l}57(47.10 \%) \\
64(52.89 \%) \\
\end{array}$ & $0.151(1), 0.697$ \\
\hline $\begin{array}{l}\text { Any other psychoactive } \\
\text { substance use } \\
\text { Yes } \\
\text { No }\end{array}$ & $\begin{array}{l}61(77.21 \%) \\
18(22.78 \%)\end{array}$ & $\begin{array}{l}26(21.48 \%) \\
95(78.51 \%)\end{array}$ & $60.393(1),<0.01 *$ \\
\hline
\end{tabular}




\begin{tabular}{|l|l|l|l|}
\hline $\begin{array}{l}\text { Substance use disorders vs } \\
\text { Schizophrenia and other } \\
\text { psychotic disorders }\end{array}$ & $\begin{array}{l}28(35.4) \\
23(29.1)\end{array}$ & $\begin{array}{l}9(11.3) \\
60(75.9)\end{array}$ & $24.093(1),<0.01^{*}$ \\
\hline $\begin{array}{l}\text { Substance use disorders vs } \\
\text { Mood disorders and other }\end{array}$ & $28(35.4$ & $9(11.3)$ & $7.757(1), 0.005^{*}$ \\
\hline $\begin{array}{l}\text { Schizophrenia and } \\
\text { psychotic disorders vs }\end{array}$ & $23(29.1)$ & $60(75.9)$ & $4.416(1), 0.036^{*}$ \\
Mood disorders & $24(30.3)$ & $28(35.4)$ & \\
\hline
\end{tabular}

$* \mathrm{p}<0.05=$ Significant

\section{Discussion}

In the current study, the prevalence of tobacco use in psychiatric inpatients was found to be $39.5 \%$, and the results are in line with other Indian studies, ${ }^{14}$ but contrasts with western studies where the prevalence is nearly $50-80 \% .^{5,18}$ This difference in prevalence rates might be due to the differences in cultural values, income, distribution and availability of tobacco across various countries. ${ }^{18}$ The prevalence of tobacco use in psychiatric patients is high when compared to general population (28.5\%), ${ }^{3}$ and is likely to be associated with high morbidity and mortality because of tobacco related medical conditions than in general population. ${ }^{19}$

In the current study, tobacco use is significantly more common in substance use disorders when compared to schizophrenia and other psychotic disorders $(\chi 2=24.093$, $\mathrm{p}<0.01)$ and mood disorders $(\chi 2=7.757, \mathrm{p}=0.005)$. Further, in our study we found significant association between tobacco use and comorbid other substance use $(\mathrm{p}<0.01)$. A recent study also found that tobacco use is associated with other comorbid substance use, ${ }^{15}$ and specifically, smoking tobacco is prevalent in $77 \%$ to $88 \%$ of patients with substance use problems..$^{20,21}$ Nicotine in tobacco and primary psychoactive component in other drugs of abuse share a common mechanism, where, release of neurotransmitters, especially dopamine in mesolimbic pathway, is thought to be involved in developing dependence. ${ }^{22}$ Mental illness like alcohol dependence and tobacco dependence share some common genetic factors leading to cooccurrence of alcohol and nicotine use. ${ }^{23}$ Thus, tobacco use often coexist with other substances and is regarded as a gateway drug for other substances. ${ }^{24}$ It has significant clinical considerations as comorbid tobacco use in substance use disorders may hamper the success of quitting the other substance use..$^{25}$ Nicotine in tobacco products, is known to induce cytochrome $\mathrm{P} 450$, particularly CYP1A2, which is involved in metabolism of psychotropic medications, thus hampering treatment of primary psychiatric illness. ${ }^{26,27}$ Further, management of tobacco use is usually neglected as the patients primarily present for the management of other psychiatric conditions. Hence there is a need to focus on the adequate management of tobacco use as well along with primary psychiatric conditions.

In our study, tobacco use was significantly more in mood disorders when compared to schizophrenia and other psychotic disorders, in line with previous study, ${ }^{14}$ however, most of the studies have established strong association between smoking and schizophrenia. ${ }^{18}$ It can be explained that in the current study, only psychiatric inpatients were taken and majority of the mood disorder patients in the current study were diagnosed to have mania with psychotic symptoms. Nicotine has an inhibitory effect on monoamine oxidase inhibitor leading to increased levels of other neurotransmitters thus enhancing the mood of the patient. ${ }^{28,29}$ Moreover, disinhibition and substance taking behavior are more common in manic episodes and smoking has been related to the presence of psychotic symptoms in mood disorders. ${ }^{30}$ Hence in the current study, tobacco use might have been more in mood disorders compared to schizophrenia and other psychotic disorders. However, replicative studies are needed to confirm the above finding.

Other significant finding of the current study was that in our study, tobacco use was significantly associated with gender and males are more likely to use tobacco compared to females $(\chi 2=20.820, p<0.01)$, in line with previous study. ${ }^{13,14}$ It can be explained as in India, tobacco use among females is still socially unacceptable in many cultures. ${ }^{31}$ In the current study, tobacco use was found to be significantly associated with employment status as tobacco users were more likely to be employed compared to unemployed $(p=0.005)$ and our finding is in line with previous study. ${ }^{15} \mathrm{~A}$ possible explanation could be economic independence associated with employment attributing for the easier procurement of tobacco. ${ }^{32}$

Strength of the study were that consecutive sampling technique was employed which probably yields unbiased selection of sample. All the psychiatric illness were included in the current study, hence estimating the prevalence in a heterogenous psychiatric population unlike in most studies which assessed in selected psychiatric population. We assessed both forms of tobacco use (smokeless and smoking) for estimating the overall tobacco burden in psychiatric population. However, this study has several limitations that should be noted. Only admitted psychiatric patients were included. Therefore, results may not be applicable to outpatients. The study was conducted in a tertiary care psychiatric hospital which has mental hospital setting, where usually patients with severe mental illness get admitted as in our study, hence results cannot be generalized to the general hospital setting. We did not compare the tobacco use in general population which might help in better understanding about the burden of tobacco use in this population. Substance 
use details were taken from patients and informants only and no confirmatory tests were conducted.

\section{Conclusion}

Prevalence of tobacco use is high among psychiatric patients. Specifically, tobacco use is more in substance use disorders followed by mood disorders and Schizophrenia and other psychotic disorders. Given the harmful consequences and its interference in treatment of the primary psychiatric conditions, there is a need to focus on the adequate management of tobacco use along with primary psychiatric conditions.

\section{Acknowledgement}

We are thankful to Superintendent, IMH, Dr. Uma Shankar for permitting us to carry out the study.

\section{Conflict of Interest}

None.

\section{Source of Funding}

None.

\section{References}

1. Bilano V, Gilmour S, Moffiet T, d'Espaignet ET, Stevens GA, Commar A, et al. Global trends and projections for tobacco use, 1990-2025: An analysis of smoking indicators from the WHO comprehensive information systems for tobacco control. Lancet 2015;385:966-76.

2. Stanaway JD, Afshin A, Gakidou E. Global, regional, and national comparative risk assessment of 84 behavioural, environmental and occupational, and metabolic risks or clusters of risks for 195 countries and territories, 1990-2017: a systematic analysis for the Global Burden of Disease Study 2017. Lancet 2018;392:1923-94.

3. Tata Institute of Social Sciences (TISS), Mumbai and Ministry of Health and Family Welfare, Government of India. Global Adult Tobacco Survey GATS 2 India 2016-17.

4. Smith P, Mazure C, McKee S. Smoking and mental illness in the US population. Tob Control. 2014;23(e2):e147-53.

5. Lasser K, Boyd J, Woolhandler S, Himmelstein D, McCormick $\mathrm{D}$, Bor $\mathrm{D}$ et al. Smoking and mental illness. JAMA. 2000;284(20):2606

6. de Leon J, Diaz FJ. A meta-analysis of worldwide studies demonstrates an association between schizophrenia and tobacco smoking behaviors. Schizophr Res. 2005; 76(2-3):13557. doi:10.1016/j.schres.2005.02.010.

7. Breslau N, Kilbey M, Andreski P. Nicotine dependence, major depression, and anxiety in young adults. Arch Gen Psychiatry. 1991;48(12):1069-74. doi:10.1001/archpsyc.1991.01810360033005

8. Vatss S, Mehar H, Bhatia T, Richard J, Gur RC, Gur RE et al. Patterns of tobacco consumption among Indian men with schizophrenia compared to their male siblings. Psychiatry Investig. 2012;9(3):245.

9. Callaghan RC, Veldhuizen S, Jeysingh T, Orlan C, Graham C, Kakouris $\mathrm{G}$ et al. Patterns of tobacco-related mortality among individuals diagnosed with schizophrenia, bipolar disorder, or depression. J Psychiatr Res. 2014;48(1):102-10.

10. Molla Z, Dube L, Krahl W, Soboka M. Tobacco dependence among people with mental illness: a facility-based cross sectional study from Southwest Ethiopia. BMC Res Notes. 2017;10(1):289.
11. Icick R, Melle I, Etain B, Ringen PA, Aminoff SR, Leboyer M et al. Tobacco smoking and other substance use disorders associated with recurrent suicide attempts in bipolar disorder. $J$ Affect Disord. 2019; 256:348-57.

12. de Oliveira RM, Siqueira Júnior AC, Santos JL, Furegato AR. Nicotine dependence in the mental disorders, relationship with clinical indicators, and the meaning for the user. Rev Lat Am Enfermagem. 2014;22(4):685-92. doi:10.1590/01041169.3549.2468

13. Milani HS, Kharaghani R, Safa M. Pattern of smoking and nicotine dependence in patients with psychiatric disorders. Tanaffos. 2012;11(1):55-60. HS, Kharaghani R, Safa M, et al. Pattern of smoking and nicotine dependence in patients with psychiatric disorders. Tanaffos 2012;11(1):55-60

14. Chandra PS, Carey MP, Carey KB, Jairam KR, Girish NS, Rudresh HP et al.. Prevalence and correlates of tobacco use and nicotine dependence among psychiatric patients in India. Addict Behav. 2005;30(7):1290-9.

15. Kar SK, Roy P, Dalal PK. Clinical correlates of tobacco use among hospitalized psychiatric patients. J Clin Sci. 2020;17(2):24.

16. Ebbert JO, Patten CA, Schroeder DR. The Fagerström test for nicotine dependence-smokeless tobacco (FTND-ST). Addict Behav 2006;31(9):1716-21.

17. Heatherton TF, Kozlowski LT, Frecker RC, Fagerstrom KO. The Fagerström test for nicotine dependence: a revision of the Fagerstrom Tolerance Questionnaire. Br J Addict 1991;86(9):1119-27.

18. Vanable PA, Carey MP, Carey KB, Maisto SA. Smoking among psychiatric outpatients: relationship to substance use, diagnosis, and illness severity. Psychol Addict Behav 2003;17(4):259.

19. Lim S, Vos T, Flaxman A, et al. A comparative risk assessment of burden of disease and injury attributable to 67 risk factors and risk factor clusters in 21 regions, 1990-2010: a systematic analysis for the global burden of disease study 2010. Lancet. 2012;380(9859):2224-60.

20. Guydish J, Passalacqua E, Tajima B, Chan M, Chun J, Bostrom A. Smoking prevalence in addiction treatment: a review. Nicotine Tob Res. 2011;13(6):401-11. doi: 10.1093/ntr/ntr048.

21. Kelly PJ, Baker AL, Deane FP, Kay-Lambkin FJ, Bonevski B, Tregarthen J. Prevalence of smoking and other health risk factors in people attending residential substance abuse treatment. Drug Alcohol Rev. 2012;31(5):638-44.

22. Di Chiara G. Role of dopamine in the behavioural actions of nicotine related to addiction. Eur J Pharmacol. 2000;393(13):295-314. doi: 10.1016/s0014-2999(00)00122-9. PMID: 10771025.

23. Young SE, Rhee SH, Stallings MC, Corley RP, Hewitt JK. Genetic and environmental vulnerabilities underlying adolescent substance use and problem use: general or specific? Behav Genet 2006;36(4):603-15. doi: 10.1007/s10519-0069066-7.

24. Ren M, Lotfipour S. Nicotine Gateway Effects on Adolescent Substance Use. West J Emerg Med. 2019;20(5):696-709. doi: 10.5811/westjem.2019.7.41661.

25. Rabin RA, George TP. A review of co-morbid tobacco and cannabis use disorders: Possible mechanisms to explain high rates of co-use. Am J Addict. 2015;24(2):105-16.

26. Corvin A, O'Mahony E, O'Regan M, Comerford C, O'Connel $\mathrm{R}$, Craddock $\mathrm{N}$ et al. Cigarette smoking and psychotic symptoms in bipolar affective disorder. Br J Psychiatry. 2001;179:35-38.

27. Desai HD, Seabolt J, Jann MW. Smoking in patients receiving psychotropic medications: a pharmacokinetic perspective. CNS Drugs 2001;15(6):469-94. doi: 10.2165/00023210-20011506000005. PMID: 11524025. 
28. Berlin I, Anthenelli RM. Monoamine oxidases and tobacco smoking. Int J Neuropsychopharmacol. 2001;4(1):33-42. doi:10.1017/S1461145701002188. PMID: 11343627.

29. Shulman KI, Herrmann N, Walker SE. Current place of monoamine oxidase inhibitors in the treatment of depression. CNS Drugs 2013;27(10):789-97 doi:10.1007/s40263-0130097-3

30. Desai HD, Seabolt J, Jann MW. Smoking in patients receiving psychotropic medications: a pharmacokinetic perspective. CNS Drugs 2001;15(6):469-94. doi: 10.2165/00023210-20011506000005. PMID: 11524025 .

31. Shah S, Dave B, Shah R, Mehta TR, Dave R. Socioeconomic and cultural impact of tobacco in India. J Family Med Prim Care 2018;7(6):1173-6. doi: 10.4103/jfmpc.jfmpc_36_18. PMID: 30613493; PMCID: PMC6293949.
32. Sorensen G, Gupta PC, Pednekar MS. Social disparities in tobacco use in Mumbai, India: the roles of occupation, education, and gender. Am J Public Health 2005;95(6):1003-8. doi: 10.2105/AJPH.2004.045039. PMID: 15914825; PMCID: PMC1449300.

How to cite this article: Swetha P, Kethawath SM, Rao SS Tobacco use and its clinical correlates among Psychiatric inpatients at a tertiary care Psychiatric Hospital: A cross sectional study. Telangana. Telangana $J$ Psychiatry. 2020;6(2):130-136. 